\title{
STUDY OF RESISTIVE INDEX IN VARIOUS STAGES OF LIVER CIRRHOSIS AND ITS SIGNIFICANCE IN CALCULATING THE RISK FOR HEPATORENAL SYNDROME
}

\author{
J.S. Sikarwar ${ }^{1}$, Shilpi Muchhoria², Rashmi Singh ${ }^{3}$, Harish Bhujade ${ }^{4}$, Vrashbhan Ahirwar ${ }^{5}$
}

\section{HOW TO CITE THIS ARTICLE:}

J.S. Sikarwar, Shilpi Muchhoria, Rashmi Singh, Harish Bhujade, Vrashbhan Ahirwar. "Study of Resistive Index in various stages of Liver Cirrhosis and its significance in Calculating the Risk for Hepatorenal Syndrome". Journal of Evolution of Medical and Dental Sciences 2014; Vol. 3, Issue 05, February 03; Page: 1195-1205,

DOI: $10.14260 /$ jemds/2014/1968

\begin{abstract}
AIM: To evaluate resistive index in various stages of liver cirrhosis and to determine its significance in developing hepatorenal syndrome. METHODS: Study included 60 cirrhotic patients divided into 4 groups (15 patients each): compensated liver cirrhosis (group A), diuretic responsive ascites (group B), refractory ascites (group C), hepatorenal syndrome (group D) and ten healthy persons as control group (E). All patients subjected to detailed history taking and clinical examination. Laboratory investigations included simple urine analysis, complete blood picture, liver function tests, blood urea and serum creatinine, serum sodium and serum potassium, and protein concentration. Ultrasonographic examination and renal duplex Doppler were under taken to assess the Resistive index. RESULTS: The RI of interlobar and arcuate arteries were significantly higher in all patient groups than in control group ( $\mathrm{p}<0.05)$, the RI was significantly higher in patients with refractory ascites than in patients with diuretic responsive ascites, and also in patient of diuretic responsible ascites than in patients with compensated cirrhosis ( $\mathrm{p}<0.05$ ), in patient with hepatorenal syndrome than in patient with diuretic responsive ascites and patients with compensated cirrhosis $(\mathrm{p}<0.05)$. Also Creatinine levels \& blood urea levels in patients with the hepatorenal syndrome was significantly higher than that of other different groups $(p<0.05)$ but there was no significant change in creatinine levels between patients with compensated cirrhosis and control group. While creatinine levels in patient with diuretic responsive ascites was significantly higher than that in patient with compensated cirrhosis $(\mathrm{p}<0.05)$ there was no significant change between patient with diuretic responsive ascites and patient with refractory ascites. CONCLUSION: Resistive index increases with degree of hepatic decompensation. Renal duplex ultrasound is a noninvasive, simple and easy method to study intrarenal hemodynamics in patients with liver cirrhosis may predict patients at risk of hepatorenal impairment.
\end{abstract}

KEYWORDS: Liver Cirrhosis, Hepatorenal Syndrome, Renal Doppler.

INTRODUCTION: Renal hemodynamic changes with intense intrarenal vasoconstriction begin early in the course of liver disease before changes in the level of serum urea and serum creatinine ${ }^{1}$. Patients with liver cirrhosis and portal hypertension develop circulatory dysfunction characterized by disturbance in systemic and renal hemodynamics. Hepatorenal syndrome (HRS) is a "functional" and reversible form of renal failure that occurs in patients with advanced chronic liver disease. The distinctive hallmark feature of HRS is the intense renal vasoconstriction caused by interactions between systemic and portal hemodynamics. This results in inactivation of vasoconstrictors and suppression of vasodilators in the renal circulation. Although the assessment of kidney function is of great clinical importance in patients with liver cirrhosis and ascites, serum creatinine and even 
creatinine clearance are not accurate indicators of renal impairment in patients with advanced liver cirrhosis. Most patients with hepatorenal syndrome do not have a satisfactory response to diuretic therapy2. Doppler ultrasonography is a non-invasive tool for the assessment of vascular patency. Although, a diagnostic grey Scale ultrasonography is widely employed in the evaluation of cirrhotic patients, and Doppler is rarely used ${ }^{3}$. Time velocity waveform analysis of Doppler signals from small intrarenal arteries allows for estimation of intrarenal vascular resistance. Resistive index (RI) is the most widely used index for estimation of intrarenal vascular resistance ${ }^{4}$. An elevated renal RI has been observed in various conditions associated with elevated renal vascular resistance like kidney obstruction, acute tubular necrosis and hemolytic uremic syndrome and is detected in liver disease related functional kidney failure. ${ }^{5}$. Kastelan et al, have demonstrated that renal duplex Doppler of interlobar arteries is a simple, effective and non-invasive method and enables the early detection of renal hemodynamic disturbances in patients with liver cirrhosis even before renal dysfunction becomes clinically evident. Moreover it makes possible the identification of a subgroup of patients with liver cirrhosis who are at higher risk for developing HRS6. Sacerdoti et al, have found that renal arterial resistance indices evaluated by duplex ultrasonography increase in the non-ascitic phase of cirrhosis and are higher in the ascitic phase, particularly during diuretic treatment. This non-invasive method may be applied to pathophysiological and clinical studies of the renal functional impairment of cirrhosis ${ }^{7}$.

METHODS: Study was conducted in Radiodiagnosis department in association with departments of medicine Gajra Raja Medical College, J. A. group of hospitals, Gwalior. The study was done during period from October 2012 to October 2013. The patients divided into 4 groups (15 in each): Group A with compensated liver cirrhosis, Group B included with diuretic responsive ascites, Group C: refractory ascites and Group D: hepatorenal syndrome diagnosed clinically and by renal chemistry, 10 healthy persons taken as a control group (Group E). Study was conducted strictly upon the guidelines issued by the Radiodiagnosis department, and ethical committee. All patients provided informed written consent, subjected to clinical assessment, history of chronic liver disease especially bleeding tendency, ascites, jaundice, and encephalopathy. Patients were excluded if there was a history diabetes mellitus, hypertension, and nephrotoxic drug intake. Laboratory investigations included simple urine analysis, complete blood picture, total and direct bilirubin, ALT, AST, alkaline phosphatase, total proteins, serum albumin and prothrombin time, blood urea and serum creatinine, serum sodium and serum potassium. Ultrasonographic examination was performed on all patients and the control group at the Radiology Department Jayarogya Hospital, Gwalior. Equipment used was Nemio 30, Toshiba ultrasonography machine with high frequency linear probes 5 to $7 \mathrm{MHz}$ and Curvilinear array transducer 3 to $6 \mathrm{MHz}$ with a real time B mode imaging system with pulsed wave and color Doppler facilities. All subjects were studied in morning after overnight fasting, underwent Abdominal and Pelvic Ultrasonography. The liver, spleen, kidneys, and ascites were evaluated and renal duplex Doppler ultrasonography to assess resistive index. Patients were examined in supine as well as in right and left lateral positions. The classic midline approach of the origin of the main renal arteries was done by placing the transducer in the epigastrium with slight inclination to the left to visualize the abdominal aorta in a coronal section with its main abdominal branches (celiac and superior mesenteric arteries) followed by a cross-sectional view of the abdominal aorta just distal to the origin of the superior mesenteric artery in order to visualize the renal arteries. The origin of the 
two renal arteries was determined by two important landmarks (i. e. the superior mesenteric artery and the renal vein). The peak systolic velocity of the aorta was measured. Waveform recording was first obtained from the abdominal aorta just proximal to the origin of the renal arteries. Recordings were obtained a few centimeters from the origin of the aorta to avoid high velocity turbulence at the origin. The renal artery was then traced down to the hilum of the corresponding kidney. The resistive index were calculated from each interlobar artery and arcuate artery according to special software fitted to the computer of USG machine.

Statistical analysis: Data were checked, coded, entered and analyzed using SPSS (The Statistical Package for Social Sciences) version 10.0 software.

The results were collected, presented and analyzed using the 0.05 significance level and the 0.01 high significance level, $p$ value of $<0.05$ was considered significant.

Statistical methods included: descriptive methods such as mean, standard deviation, frequency distribution (minimal and maximal), independent t-test, one-way ANOVA, quantitative data to test the significance of differences between the mean values of the study variables for comparison between more than two groups and Pearson correlation, for determination of the correlation between the age, and sex of different groups and the resistive index and the correlation between urinary sodium and the resistive index in different groups

RESULTS: The graph 1 shows the age distribution among control group. Maximum number of patients in control group were between 36-45 years old.

Graph 2- Among the group A maximum number of patient were of $36-45$ years of age i.e. $4 \%$ and then 15-25 and 46-55 years of age i.e. 3\%. Among the group B maximum no. of patient were 4655 years of age which was followed by 26-35 \& 36-45 years of age. Among the group $C$ maximum number of patient were of 46-55 years of age $(n=5)$ which was followed by 56-65 of age $(n=4)$. Among the group B maximum number of patient were of $56-65$ years of age $(n=7)$ which was followed by 56-65 years of age $(n=7)$ which was then followed by $46-55$ years of age $(n=4)$.

\begin{tabular}{|c|c|c|c|c|c|c|c|c|c|}
\hline & $\begin{array}{c}\mathrm{Na} \\
(\mathrm{meq} / \mathrm{dl})\end{array}$ & $\begin{array}{c}\mathrm{K} \\
(\mathrm{meq} / \mathrm{dl})\end{array}$ & Albumin & $\begin{array}{c}\text { Creatinine } \\
(\mathrm{mg})\end{array}$ & $\begin{array}{c}\text { Urea } \\
(\mathrm{mg})\end{array}$ & $\begin{array}{c}\text { Bilirubin } \\
\text { (total in } \\
\mathrm{mg} / \mathrm{dl}\end{array}$ & $\begin{array}{c}\text { SGOT } \\
(\mathrm{IU} / \mathrm{L})\end{array}$ & $\begin{array}{c}\text { SGPT } \\
(\mathrm{IU} / \mathrm{L})\end{array}$ & $\begin{array}{c}\text { Renal } \\
\text { Doppler } \\
\mathrm{RI}\end{array}$ \\
\hline Mean & 138.47 & 4.18 & 3.68 & 0.90 & 23.60 & 2.46 & 55.33 & 52.67 & 0.5253 \\
\hline SD & 5.32 & 0.55 & 0.49 & 0.35 & 8.38 & 0.92 & 8.97 & 7.64 & 0.1488 \\
\hline \multicolumn{7}{|c}{ Corr. } \\
\hline
\end{tabular}

Table - 1: Group A

The above table includes Group A i.e. patients of uncomplicated Cirrhosis, shows that mean $\mathrm{Na}^{+}$in the group was 138.47 with SD of 5.32 which was in the normal range. Whereas mean $\mathrm{K}^{+}$value was 4.18 S.D. of 0.55 and albumin was 3.68 with SD 0.49 and Serum Bilirubin level was 2.46 with SD 0.92, Mean SGOT was 55.33 with SD 8.97, and Mean SGPT was 52.67 with SD 7.64. Mean Blood urea in the group was 23.60 with SD 8.38 and mean creatinine value 0.90 with SD 0.35 and Mean RI Value 0.53 with SD 0.15 .

Upon correlation, the values obtained in color Doppler parameters with those of hematological parameter, the coefficient of co-relation between blood urea \& mean RI was 0.20. 
This indicates that positive correlation exists between the values of RI \& Blood Urea. It is observed that increased RI value in cirrhotic patients of group A was associated with corresponding increased Blood urea level.

The quantitative estimation of level of increase in blood urea with level of increase in RI could not be obtained because of the lack of sensitivity of laboratory investigations to correlate with small changes in RI.

\begin{tabular}{|c|c|c|c|c|c|c|c|c|c|}
\hline & $\begin{array}{c}\mathrm{Na} \\
(\mathrm{meq} / \mathrm{dl})\end{array}$ & $\begin{array}{c}\mathrm{K} \\
(\mathrm{meq} / \mathrm{dl})\end{array}$ & Albumin & $\begin{array}{c}\text { Creatinine } \\
(\mathrm{mg})\end{array}$ & $\begin{array}{c}\text { Urea } \\
(\mathrm{mg})\end{array}$ & $\begin{array}{c}\text { Bilirubin } \\
\text { (total in } \\
\mathrm{mg} / \mathrm{dl}\end{array}$ & $\begin{array}{c}\text { SGOT } \\
(\mathrm{IU} / \mathrm{L})\end{array}$ & $\begin{array}{c}\text { SGPT } \\
(\mathrm{IU} / \mathrm{L})\end{array}$ & $\begin{array}{c}\text { Renal } \\
\text { Doppler } \\
\mathrm{RI}\end{array}$ \\
\hline Mean & 144.93 & 4.18 & 3.75 & 1.25 & 34.47 & 3.86 & 111.27 & 70.20 & 0.62 \\
\hline SD & 7.44 & 0.62 & 0.32 & 0.66 & 10.67 & 5.22 & 147.98 & 99.84 & 0.09 \\
\hline \multicolumn{8}{|c|}{ Corr. } \\
\hline \multicolumn{10}{|c|}{ Table - 2: Group B }
\end{tabular}

The above table includes Group B i.e. Cirrhosis patients who was responding to treatment (diuretic etc.), shows that mean $\mathrm{Na}^{+}$in the group was 144.93 with SD of 7.44 . Whereas mean $\mathrm{K}^{+}$value was 4.18 S.D. of 0.62 and albumin was 3.75 with SD 0.32 and Serum Bilirubin level was 3.86 with SD 5.22, Mean SGOT was 111.27 with SD 147.98, and Mean SGPT was 70.20 with SD 99.84. These indices are raised as compared to Group A.

Mean Blood urea in the group was 34.47 with SD 10.67 and mean creatinine value 1.25 with SD 0.66 and Mean RI Value 0.62 with SD 0.09.

Upon correlation, the values obtained in color Doppler parameters with those of hematological parameter, the coefficient of co-relation between blood urea \& mean RI was 0.26197.

This indicates that positive correlation exists between the values of RI\& Blood Urea. It is observed that increased RI value in cirrhotic patients of group B was associated with corresponding increased Blood urea.

\begin{tabular}{|c|c|c|c|c|c|c|c|c|c|}
\hline & $\begin{array}{c}\mathrm{Na} \\
(\mathrm{meq} / \mathrm{dl})\end{array}$ & $\begin{array}{c}\mathrm{K} \\
(\mathrm{meq} / \mathrm{dl})\end{array}$ & Albumin & $\begin{array}{c}\text { Creatinine } \\
(\mathrm{mg})\end{array}$ & $\begin{array}{c}\text { Urea } \\
(\mathrm{mg})\end{array}$ & $\begin{array}{c}\text { Bilirubin } \\
(\text { total in } \\
\mathrm{mg} / \mathrm{dl}\end{array}$ & $\begin{array}{c}\text { SGOT } \\
(\mathrm{IU} / \mathrm{L})\end{array}$ & $\begin{array}{c}\text { SGPT } \\
(\mathrm{IU} / \mathrm{L})\end{array}$ & $\begin{array}{c}\text { Renal } \\
\text { Doppler } \\
\mathrm{RI}\end{array}$ \\
\hline Mean & 144.73 & 4.12 & 2.40 & 1.31 & 41.20 & 5.74 & 78.87 & 42.73 & 0.64 \\
\hline SD & 7.64 & 0.53 & 0.53 & 0.61 & 19.07 & 4.76 & 36.26 & 19.72 & 0.14 \\
\hline \multicolumn{7}{|c|}{ Corr. } \\
Table - 3: Group C
\end{tabular}

Above table includes Group C i.e. patients of complicated Cirrhosis non responding to treatment, shows that mean $\mathrm{Na}^{+}$in the group was 144.73 with $\mathrm{SD}$ of 7.64. Whereas mean $\mathrm{K}^{+}$value was 4.12 S.D. of 0.53 and albumin was 2.40 with SD 0.53 and Serum Bilirubin level was 5.74 with SD 4.7, Mean SGOT was 78.87 with SD 36.26, and Mean SGPT was 42.73 with SD 19.72.

Mean Blood urea in the group was 41.20 with SD 19.07 and mean creatinine value 1.31 with SD 0.61 and Mean RI Value 0.64 with SD 0.14

Upon correlation the values obtained in color Doppler parameters with those of hematological parameter, the coefficient of co-relation between blood urea \& mean RI was 0.2762. 
This indicates that positive correlation exists between the values of RI \& Blood Urea. It is observed that increased RI value in cirrhotic patients of group $\mathrm{C}$ was associated with corresponding increased Blood urea level.

\begin{tabular}{|c|c|c|c|c|c|c|c|c|c|}
\hline & $\begin{array}{c}\mathrm{Na} \\
(\mathrm{meq} / \mathrm{dl})\end{array}$ & $\begin{array}{c}\mathrm{K} \\
(\mathrm{meq} / \mathrm{dl})\end{array}$ & Albumin & $\begin{array}{c}\text { Creatinine } \\
(\mathrm{mg})\end{array}$ & $\begin{array}{c}\text { Urea } \\
(\mathrm{mg})\end{array}$ & $\begin{array}{c}\text { Bilirubin } \\
(\text { total in } \\
\mathrm{mg} / \mathrm{dl}\end{array}$ & $\begin{array}{c}\text { SGOT } \\
(\mathrm{IU} / \mathrm{L})\end{array}$ & $\begin{array}{c}\text { SGPT } \\
(\mathrm{IU} / \mathrm{L})\end{array}$ & $\begin{array}{c}\text { Renal } \\
\text { Doppler } \\
\mathrm{RI}\end{array}$ \\
\hline Mean & 224.40 & 2.67 & 1.84 & 13.12 & 100.87 & 19.53 & 501.20 & 293.61 & 0.75 \\
\hline SD & 55.27 & 0.61 & 0.58 & 2.85 & 14.78 & 8.23 & 395.12 & 180.31 & 0.07 \\
\hline \multicolumn{7}{|c|}{ Corr. } \\
\hline
\end{tabular}

Table - 4: Group D

The above table includes Group D i.e. patients of hepatorenal syndrome, shows that the mean $\mathrm{Na}^{+}$in the group was 224.40 with SD of 55.27. Whereas mean $\mathrm{K}^{+}$value was 2.67 S.D. of 0.61 and albumin was 1.84 with SD 0.58 and Serum Bilirubin level was 19.53 with SD 8.23, Mean SGOT was 501.20 with SD 395.12, and Mean SGPT was 293.61 with SD 180.31.

Mean Blood urea in the group was 100.87 with SD 14.78 and mean creatinine value 13.12 with SD 2.85 and Mean RI Value 0.75 with SD 0.07.

Upon correlation the values obtained in color Doppler parameters with those of hematological parameter, the coefficient of co-relation between blood urea \& mean RI was 0.309.

This indicates that positive correlation exists between the values of RI \& Blood Urea. It is observed that increased RI value in cirrhotic patients of group D was associated with corresponding increased Blood urea level.

\begin{tabular}{|c|c|c|c|c|c|c|c|c|c|}
\hline & $\begin{array}{c}\mathrm{Na} \\
(\mathrm{meq} / \mathrm{dl})\end{array}$ & $\begin{array}{c}\mathrm{K} \\
(\mathrm{meq} / \mathrm{dl})\end{array}$ & Albumin & $\begin{array}{c}\text { Creatinine } \\
(\mathrm{mg})\end{array}$ & $\begin{array}{c}\text { Urea } \\
(\mathrm{mg})\end{array}$ & $\begin{array}{c}\text { Bilirubin } \\
\text { (total in } \\
\mathrm{mg} / \mathrm{dl}\end{array}$ & $\begin{array}{c}\text { SGOT } \\
(\mathrm{IU} / \mathrm{L})\end{array}$ & $\begin{array}{c}\text { SGPT } \\
(\mathrm{IU} / \mathrm{L})\end{array}$ & $\begin{array}{c}\text { Renal } \\
\text { Doppler } \\
\mathrm{RI}\end{array}$ \\
\hline Mean & 141.40 & 4.07 & 3.64 & 0.57 & 28.50 & 0.60 & 19.80 & 25.10 & 0.54 \\
\hline SD & 9.59 & 0.60 & 0.57 & 0.29 & 6.62 & 0.23 & 8.89 & 5.70 & 0.08 \\
\hline \multicolumn{3}{|c|}{ Corr. } \\
\hline
\end{tabular}

Table - 5: Group E

The above table includes Group E i.e. normal control group, shows that mean $\mathrm{Na}^{+}$in the group was 141.40 with SD of 9.59. Which was in the normal range? Whereas mean $\mathrm{K}^{+}$value was 4.07 S.D. of 0.60 and albumin was 3.64 with SD 0.57 and Serum Bilirubin level was 0.60 with SD 0.23, Mean SGOT was 19.80 with SD 8.89, and Mean SGPT was 25.10 with SD 5.70.all in normal range.

Mean Blood urea in the group was 28.50 with SD 6.63 and mean creatinine value 0.57 with SD 0.29 and Mean RI Value 0.54 with SD 0.08.

Upon correlation the values obtained in color Doppler parameters with those of hematological parameter, the coefficient of co-relation between blood urea \& mean RI was 0.526.

This indicates that positive correlation exists between the values of RI \& Blood Urea. It is observed that all the values of RI \& serum urea level were within normal limits among the subjects of control group. 
DISCUSSION: Hepatorenal syndrome (HRS) is reversible functional renal impairment that occurs in patients with advanced liver cirrhosis or those with fulminant hepatic failure. It is characterized by marked reduction in the glomerular filtration rate (GFR) and renal plasma flow in the absence of other causes of renalfailure ${ }^{8}$.

The hallmark of HRS is hypo perfusion of the kidney resulting from combined renal vasoconstriction and decreased total renal blood flow ${ }^{9}$. The earliest stages of this apparently functional form of kidney failure often go unrecognized because creatinine elevation occurs late in the hepatorenal syndrome ${ }^{10}$.Duplex ultrasonography is a widely used non-invasive method to assess vascular patency and blood flow in many sites. Duplex Doppler can be used to assess vascular resistance in the small intraparenchymal vessels through simple analysis of Doppler waveform by a parameter termed the resistive index (RI) ${ }^{11}$. An elevated renal RI has be observed in various conditions associate with elevated renal vascular resistance such as kidney obstruction, acute tubular necrosis and hemolytic uremic syndrome and should be detected in liver disease related functional kidney failure. ${ }^{5}$

Our aim was to study the renal resistive index of both interlobar and arcuate arteries in different stages of liver cirrhosis. Early identification of changes in the RI in patients with established liver disease who are at particular risk for the development of hepatorenal syndrome may be beneficial in directing or modifying the management. This study was carried out on 60 cirrhotic patients divided into 4 groups: Group A (compensated cirrhosis), Group B (responsive ascites), Group C (refractory ascites) and Group D (hepatorenal syndrome) and a Group-E (control) group. We observed a significant fall in the urinary sodium concentration (meq/dL) in the patient groups. Kenawi et al, reported that the urine sodium excretion in patients with chronic liver disease decreases with progression of disease and correlates with the Child-Pugh's class ${ }^{12}$.

We determined that serum Creatinine levels \& blood urea levels in patients with the hepatorenal syndrome was significantly higher than that of other different groups $(\mathrm{p}<0.05)$ but there was no significant change in creatinine levels between patients with compensated cirrhosis and control group. While creatinine levels in patient with group B was higher than that in patient with compensated cirrhosis $(\mathrm{p}<0.05)$ there was no significant change between patient with group B and patient with group $\mathrm{C}^{13}$.

Renal duplex Doppler ultrasonography was performed on the right or left kidney at the interlobar and arcuate arteries to measure the resistive index. In this study that the RI of both interlobar and arcuate arteries (renal intraparenchymal vessels) were significantly higher in all patient groups than in control group $(p<0.05)$, the RI was significantly higher in patients with refractory ascites than in patients with group $B$, and also in patient of group $B$ than in patients with compensated cirrhosis $(\mathrm{p}<0.05)$, in patient with hepatorenal syndrome than in patient with group $B$ and patients with compensated cirrhosis $(\mathrm{p}<0.05)$. The increase in renal vascular RI in cirrhotic patients with ascites can be explained by a physiological homeostatic response to vascular under filling occurring in ascitic patients. When the vascular under filling is moderate, the renal vasoactive substances are effectively counterbalanced by increased renal synthesis of prostaglandins so that renal blood flow and GFR remain normal. In contrast, when the vascular under filling is severe, intense stimulation of endogenous vasoconstrictor systems occurs, producing renal vasoconstriction and impairment of renal blood flow and GFR ${ }^{14}$.Pateron et al, concluded that intra-renal blood flow is 
preserved in cirrhotic patients by intra-renal mechanisms until the ascites becomes refractory. When this regulation fails renal ischemia causes tubular necrosis, azotemia and oliguric renal failure ${ }^{15}$.

Maroto et al, demonstrated that RI is significantly higher in decompensated cirrhotic patients with ascites than in compensated cirrhotic patients and that the RI of compensated cirrhotic patients is higher than in the controls. They reported that these results were highly sensitive and specific for the diagnosis of HRS. ${ }^{1}$ Also Masahiko et al, demonstrated that both the pulsatility and resistive indices were significantly higher in cirrhotic patients compared to controls and compared to patients with chronic hepatitis. Both indices measured by color Doppler ultrasonography were closely related to the severity of cirrhosis and showed significant correlation with increased Child-Pugh grade ${ }^{16}$.In another study Alberto et al, concluded that patients with HRS had significantly higher values of RI than those without HRS. The relative risk of developing HRS in patients with an RI $=0.70$ was high. RI is a useful indicator in patients with cirrhosis and ascites for the diagnosis and prognosis of HRS ${ }^{17}$.

In Italy, Sacerdoti et al, reported that the PI and RI were significantly higher in nonascitic cirrhotic patients than in control patients, in ascitic patients than in nonascitic patients, in ascitic patients not treated with diuretics than in nonascitic ones and in ascitic patients treated with diuretics than in those not treated. The PI and RI were significantly higher in Child-Turcotte-Pugh class $\mathrm{B}$ and $\mathrm{C}$ patients than in class A patients. This noninvasive method may be applied to pathophysiological and clinical studies of the renal functional impairment in cirrhosis7.

We conclude that renal duplex Doppler ultrasound is useful as a non-invasive method for the evaluation of the renal hemodynamic changes in cirrhotic patients with good correlation to the severity of liver disease. RI may be superior to serum creatinine levels as an indicator in patients with liver cirrhosis for the detection of patients at risk for the development of hepatorenal syndrome.

\section{REFERENCES:}

1. Maroto A, Ginès A, Saló J, Clària J, Ginès $P$, Anibarro L, et al. Diagnosis of functional renal failure of cirrhosis with Doppler sonography: prognostic value of resistive index. Hepatology.1994; 20:839-44.

2. Arroyo V, Gines P, Gerbes A, Dudley FJ, Gentilini P, Laffi G, et al. Definition and diagnostic criteria of refractory ascites and hepatorenal syndrome in cirrhosis. Hepatology. 1996; 23:16476.

3. Lomas DJ, Britton PD, Summerton CB, Seymour CA. Duplex Doppler measurements of portal vein in portal hypertension. ClinRadiol.1993; 48:311-5.

4. Platt JF, Rubin JM and Eills JH. Intrarenal arterial Doppler sonography in patients with nonobstructive renal disease: correlation of resistive index with biopsy findings. Am J Roentgenol.1990; 154:1223-7.

5. Friedman SL. Alcoholic liver disease, cirrhosis, and its major sequelae In: Cecil text book of medicine; L Goldman, C Bennet, 21st ed Saunders, Philadelphia; 2000, 153:804-12.

6. Kastelan S, Ljubicic N, Kastelan Z, Ostojic R, Uravic M. The role of duplex- doppler ultrasonography in the diagnosis of renal dysfunction and hepatorenal syndrome in patients with liver cirrhosis. Hepatogastroenterology. 2004; 51:1408-12.

7. Sacerdoti D, Bolognesi M, Merkel C, Angeli P, Gatta A. Renal vasoconstriction in cirrhosis evaluated by duplex Doppler ultrasonography. Hepatology. 1993; 17:219-24. 
8. Angeli P, Merkel C. Pathogenesis and management of hepatorenal syndrome in patients with cirrhosis. J Hepatol. 2008; 48:S93-103.

9. Cárdenas A, Uriz J, Ginès P, Arroyo V. Hepatorenal syndrome. Liver Transpl. 2000; 6:S63-71.

10. Gentilini P, Laffi G. Renal function impairment and sodium retention in liver cirrhosis. Digestion. 1989; 43:1-32.

11. Platt JF. Duplex Doppler evaluation of native kidney dysfunction: obstructive and nonobstructive disease. AJR Am J Roentgenol.1992; 158:1035-42.

12. Kenawi AM, Hamid AA, Sahar A Atty. Renal resistive index and sodium concentration as a predictor of renal dysfunction in patients with advanced liver cirrhosis. MD thesis, Cairo university 2004.

13. Nix DE, Erstad BL, Nakazato PZ, Barletta JF, Matthias KR, KruegerTS. Estimation of creatinine clearance in end-stage liver disease. Ann Pharmacother. 2006; 40:900-8.

14. Abuelo GJ. Diagnosing vascular causes of renal failure. Ann Intern Med 1995, 123:601-14.

15. Pateron D, Barriere E, Condat B, Rassiat E, Heller J, Chagneau C, et al. relationship between haemodynamic alternations and the development of ascites or refractory ascites in patients with cirrhosis. Eur J Gastroentrol Hepatol. 2001; 13:251-6.

16. Masahiko K, Murawaki Y, Kawasaki H. Renovascular resistance assessed by color Doppler ultrasonography in patients with chronic liver diseases Western Pacific Helicobacter Congress No3, pasar, Bali, INDONESIE, 2000, vol. 15, no 12, pp. H1-H33 (19ref.), pp. 1424-1429.

17. Bardi A, Sapunar J, Oksenberg D, Poniachik J, Fernández M, Paolinelli P, et al. Intrarenal arterial Doppler ultrasonography in cirrhotic patients with ascites, with and without hepatorenal syndrome. Rev Med Chil. 2002; 130:173-80.

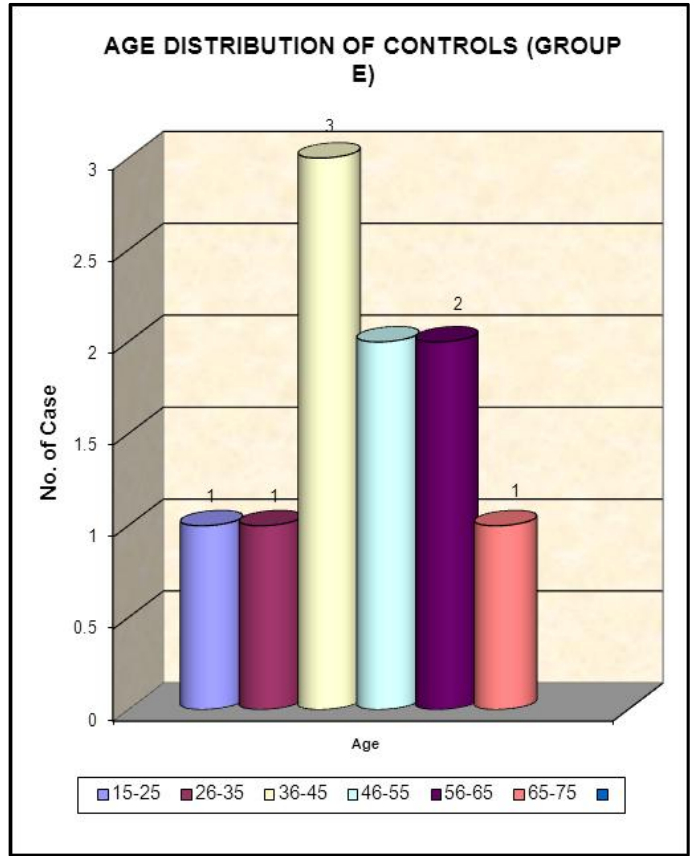

GRAPH 1 


\section{ORIGINAL ARTICLE}
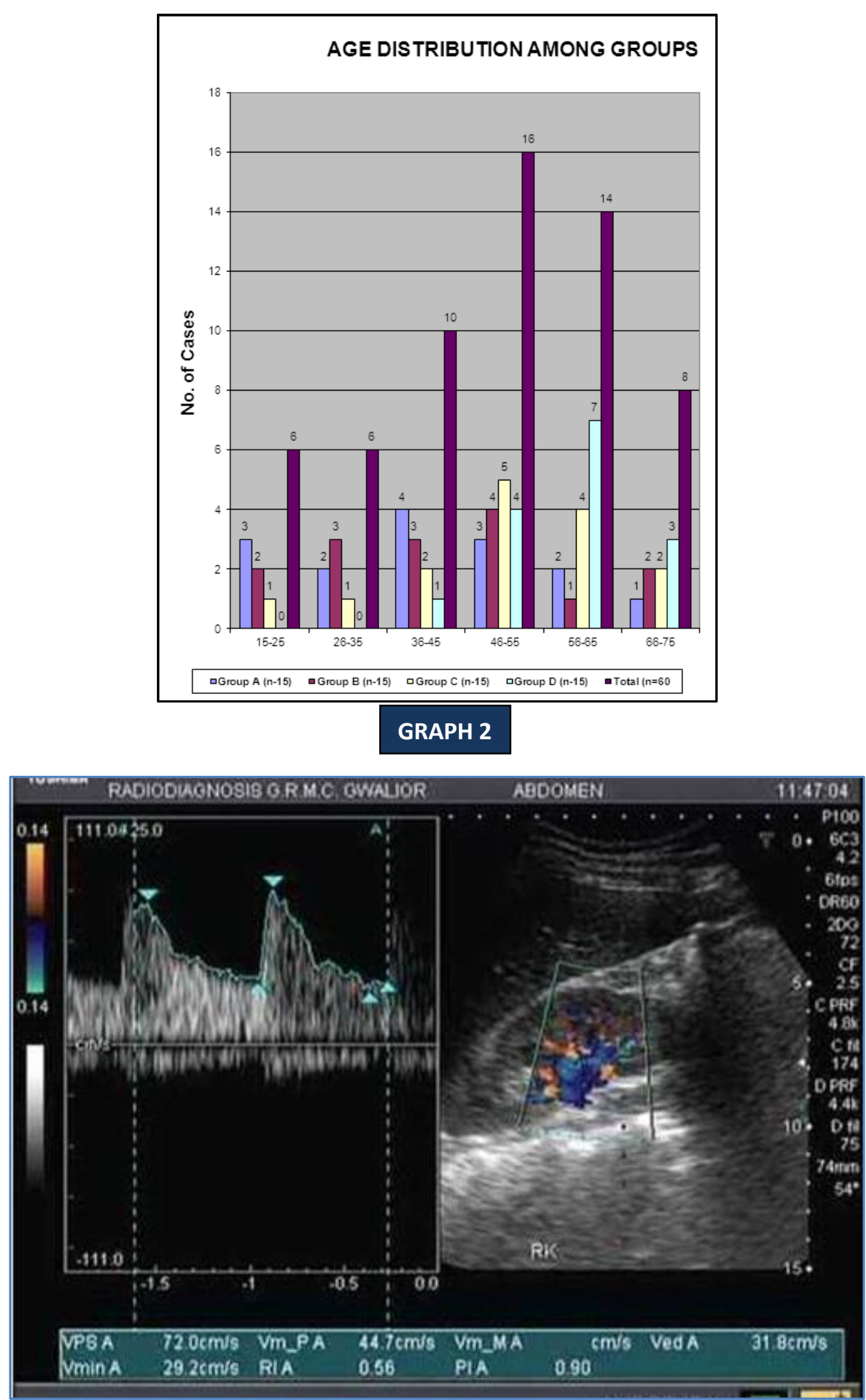

Fig. 1: NORMAL SPECTRAL WAVEFORM AT THE LEVEL OF INTERLOBAR ARTERY WITH NORMAL RESISTIVE INDEX (GROUP E) 


\section{ORIGINAL ARTICLE}

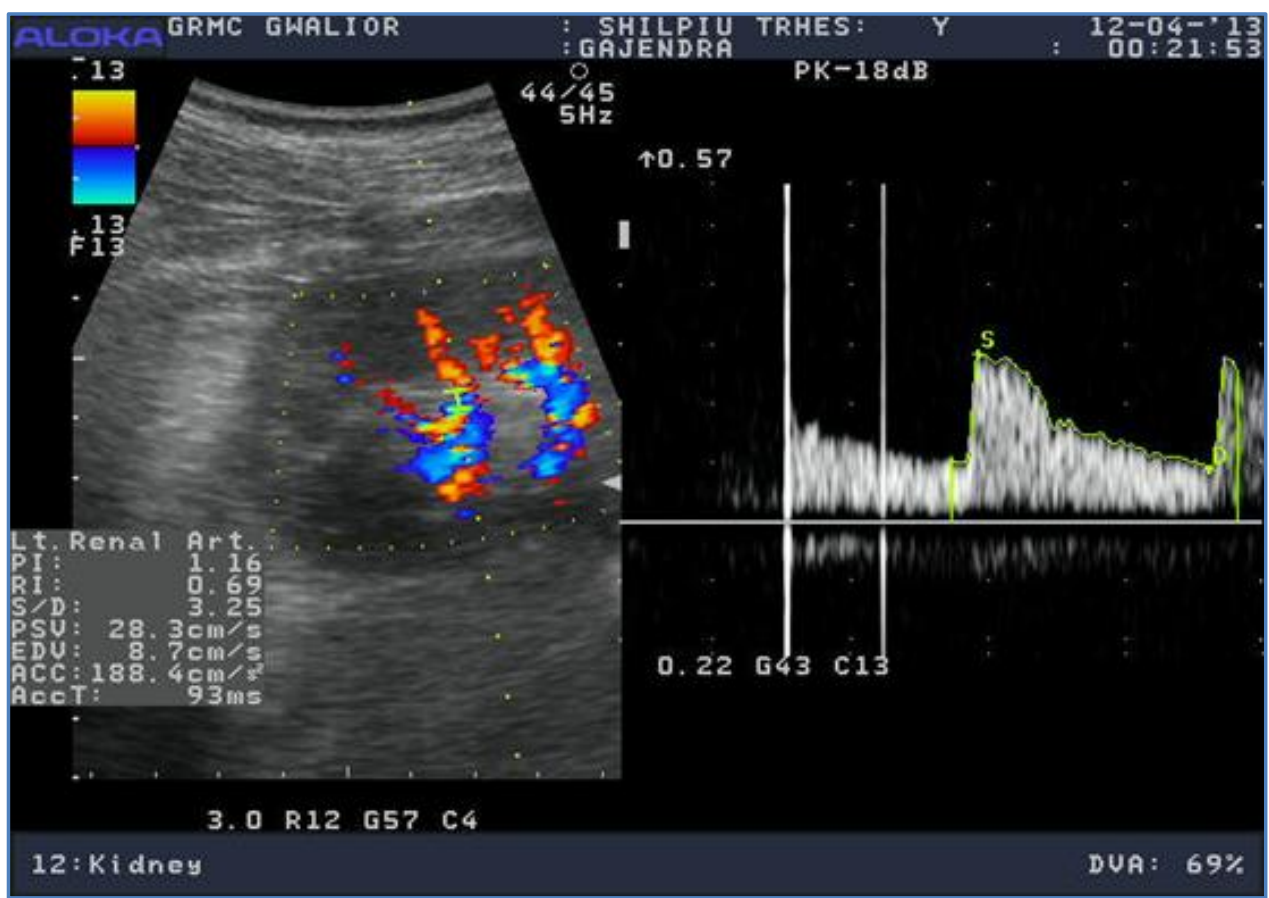

Fig. 2: renal Doppler in a patient of group $\mathbf{A}$ showing normal resistive index

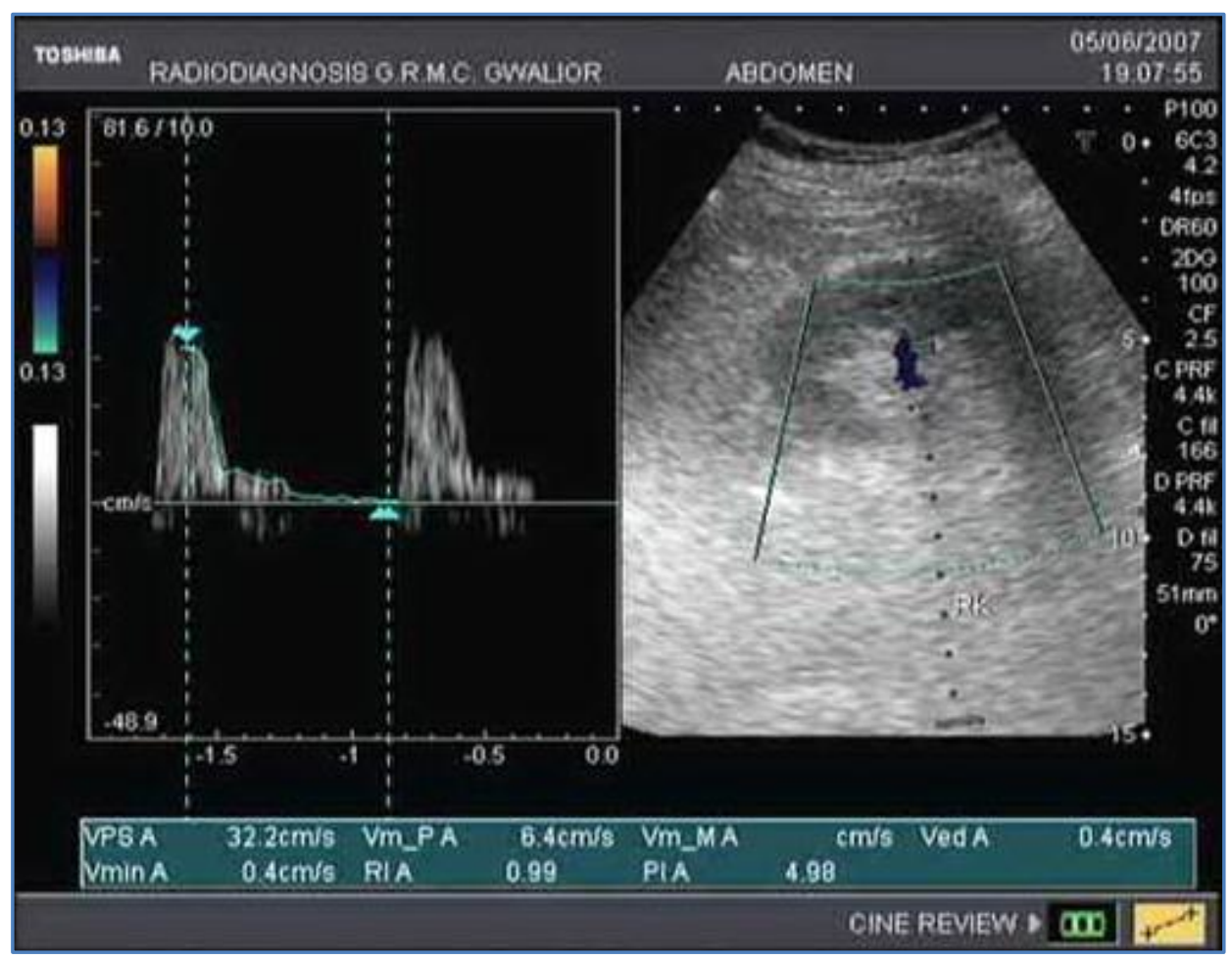

Fig. 3: patient with hepatorenal syndrome showing MARKEDLY RAISED RI WITH ALMOST TOTAL LOSS OF FORWARD DIASTOLIC FLOW 


\section{ORIGINAL ARTICLE}

\section{AUTHORS:}

1. J.S. Sikarwar

2. Shilpi Muchhoria

3. Rashmi Singh

4. Harish Bhujade

5. Vrashbhan Ahirwar

\section{PARTICULARS OF CONTRIBUTORS:}

1. Associate Professor and Head, Department of Radiodiagnosis, G.R. Medical College and J.A. Hospital, Gwalior.

2. Resident, Department of Radiodiagnosis, G.R. Medical College and J.A. Hospital, Gwalior.

3. Resident, Department of Radiodiagnosis, G.R. Medical College and J.A. Hospital, Gwalior.
4. Resident, Department of Radiodiagnosis, G.R. Medical College and J.A. Hospital, Gwalior.

5. Resident, Department of Radiodiagnosis, G.R. Medical College and J.A. Hospital, Gwalior.

\section{NAME ADDRESS EMAIL ID OF THE} CORRESPONDING AUTHOR:

Dr. Shilpi Muchhoria, G-86/22 Second Stop, Tulsi Nagar, Bhopal, (M.P), PIN - 462003.

E-mail: shilpimuchhoria212@gmail.com

Date of Submission: 11/01/2014. Date of Peer Review: 13/01/2014. Date of Acceptance: 20/01/2014. Date of Publishing: 29/01/2014. 